\title{
MUERTE DEL GUERRILLERO APODADO «EL FRANCÉS»
}

\section{DEATH OF GUERRILLERO NICKNAMED «EL FRANCÉS»}

\author{
José Mariano Agudelo Blanco \\ Patrimonio Nacional \\ ORCID: 0000-0001-8613-148X
}

Recibido el 4-2-2017 y aceptado el 16-6-2017

Resumen: El presente artículo pretende esclarecer la muerte de un mítico guerrillero antifranquista desde el análisis del sumario incoado al efecto. Pedro José Marquino, más conocido por el sobrenombre de «El Francés», resultó muerto en una emboscada de la Guardia Civil el 31 de julio de 1946. Era el Jefe de la 12. ${ }^{a}$ División de la 1. ${ }^{a}$ Agrupación Guerrillera de Extremadura-Centro, unidad que operaba por el norte de Extremadura y sur de la provincia de Salamanca. Se trata de un personaje profusamente estudiado por la bibliografía especializada en el maquis, pero ninguna indica entre sus fuentes el proceso jurídico-militar presentado.

Palabras claves: guerrilla, maquis, Franco, dictadura, represión.

Abstract: This article aims to clarify the death of a legendary anti-Franco guerrilla from the analysis of the summary initiated for this purpose. Pedro José Marquino, better known by the nickname «El Francés», was killed in an ambush by the Guardia Civil on July 31, 1946. Was the Chief of the 12th Division of the 1st Group Guerilla Extremadura-Center, unit that operated through northern Extremadura and southern Salamanca province. This is a character widely studied by the specialized literature in the maquis, but none indicates among its sources the process juridico-militar presented.

Keywords: guerrilla, maquis, Franco, dictatorship, repression. 


\section{Introducción}

La resistencia contra el franquismo inició su andadura desde el comienzo de la Guerra Civil. Así, en las zonas que quedaron rápidamente bajo control de los militares rebeldes, la represión llevada a cabo provocó la evasión al monte de muchos simpatizantes republicanos. Esta situación se generalizó tras el final del conflicto armado en 1939 y se prolongó hasta la creación de las Agrupaciones Guerrilleras a mediados de los años cuarenta. Es la etapa conocida como la de los «huidos». Con un planteamiento más defensivo que ofensivo hacia el nuevo Régimen, huyeron al monte y se ocultaron aprovechando el conocimiento del terreno y la colaboración de sus habitantes.

A partir de 1944 la lucha guerrillera se beneficia del cambio de rumbo bélico internacional. La Guerra Mundial se decantó a favor de los aliados y se consideró que la caída de Alemania e Italia conllevaría inevitablemente el final de Franco. Desde este año, tiene lugar la reorganización de los «huidos» y guerrilleros por parte de dirigentes llegados desde Francia que habían combatido al nazismo junto a la resistencia francesa. Además, el Partido Comunista de España (PCE) se encargó de cohesionar la lucha incorporando grupos de expertos políticos y militares que intentaron mejorar y coordinar las distintas Agrupaciones Guerrilleras ${ }^{1}$.

Los años que van desde 1945 hasta 1947 marcaron el apogeo de la resistencia armada en España. Durante este tiempo, la infiltración constante de guerrilleros desde Francia, la organización de los que se encontraban en el interior del país y la incorporación de nuevos enlaces permitieron extender las áreas de actividad a buena parte de la geografía española, constituyendo, por tanto, la oposición más significativa al régimen del Dictador.

Precisamente dentro de este período se encuadran los hechos analizados. Efectivamente, la muerte de «El Francés» tuvo lugar en un enfrentamiento con la Guardia Civil en la madrugada del 31 de julio de 1946. Aunque la guerrilla se encontraba en pleno apogeo, los gendarmes del

1 Al hacer esta afirmación, me estoy refiriendo al PCE como el partido político que apostó de manera plena por el movimiento guerrillero. No obstante, existieron también otras guerrillas integradas por miembros del movimiento libertario y socialistas (compartiendo en no pocas ocasiones las mismas partidas), pero de una significación menor tanto en su conjunto como en el despliegue por el territorio español. 
régimen franquistas, espoleados por el general Camilo Alonso Vega a la sazón Director General del Benemérito Instituto y amigo personal del Caudillo, desarrollaron una brutal represión contra los enlaces y colaboradores del maquis. Las nuevas técnicas de la contraguerrilla soslayaron el temerario enfrentamiento directo en los montes para centrarse en el combate contra el entorno afectivo de los guerrilleros. Seguramente resultaba mucho menos arriesgado presionar a los grupos populares de apoyo a la guerrilla que vérselas con rudos combatientes en la escabrosidad de un terreno por ellos bien conocido. Se detenía a los familiares y amigos de los maquis por esas relaciones afectivas, sin otros argumentos jurídicos. Se les encerraba en los cuartelillos $^{2}$ diseminados por los pueblos de España y se les presionaba hasta su derrumbe para conseguir la delación o cualquier otro indicio que llevara hasta los combatientes montañeses. En definitiva, se cortó el cordón umbilical de la sierra con el llano, del guerrillero con los colaboradores y enlaces del pueblo. Con la destrucción de la vasta red de apoyo a la guerrilla laboriosamente tejida, la resistencia perdió su lazarillo y se vio abocada a operar sin concierto hasta su desarticulación definitiva.

En este contexto ha de enmarcarse el trabajo actual. Las partidas guerrilleras diseminadas por el norte de Cáceres y sur salmantino, encuadradas en las 12. ${ }^{\text {a }}$ División ${ }^{3}$ mandada por «El Francés», habían sufrido el acoso de los represores del Régimen hasta llevarlas a una situación de precario e incierto futuro. Las acciones de la Guardia Civil durante el año

${ }^{2}$ Denominación popular dada a las Casas Cuarteles integrantes de la unidad básica de la Guardia Civil: el Puesto. Su demarcación abarcaba una o varias poblaciones del ámbito rural y su Comandante de Puesto, generalmente ocupado por un cabo o sargento era buen conocedor tanto de su territorio como de la sociedad que lo habitaba. Podían tener cierta autonomía en la acción inmediata; aunque, siendo un cuerpo fuertemente jerarquizado, por lo general mantenía una férrea dependencia de sus unidades superiores: la Línea, Compañía y Comandancia principalmente.

3 Así contemplaba la zona de actuación de la 12. ${ }^{a}$ División un documento de la Comandancia de la Guardia Civil en Toledo:

«12 DIVISIÓN O PARTIDA DEL «FRANCÉS». Esta división apenas actuó en la provincia de Toledo, tenía sus campamentos principales en la sierra de Gata (Cáceres) y su Sector comprendía desde el Norte del río Tajo en el límite de Toledo hasta dicha sierra, actuando en las provincias de Salamanca, Cáceres y Ávila... Esta División que era la más numerosa, llegó en período más próspero en el año 1945 a contar sobre unos 45 hombres, que se renovaban para cubrir bajas, pasando por esta División de 70 a 80 hombres». (AHPCE, caja 105, carpeta 5/3. Servicio de Información, Documentos Guardia Civil, Comandancia 104/Toledo). 
1945 y, sobre todo, 1946 consiguieron diezmar las unidades combatientes de la resistencia y doblegar su indómito espíritu de lucha por la libertad para implantar de nuevo la República. Las traiciones y chivatazos de los antiguos camaradas y colaboradores, torturados hasta la muerte en no pocos casos, dio la puntilla a un movimiento de infausto final. Cuando el jefe guerrillero fue acribillado por unos guardias civiles emboscados a su espera, se dirigía a la estafeta situada en el sitio denominado «Riscos del Pelao» en la umbría de la sierra de Peñafalcón del término municipal de Serradilla (Cáceres) ${ }^{4}$. Intentaba recabar noticias de las unidades dispersadas por la represión policial, principalmente las partidas de «Calandrio» y «Compadre» ${ }^{5}$. Con su muerte, y tras la documentación localizada, se inició todo un rosario de acciones contra el maquis que provocaron su prematuro final en la zona acotada para este trabajo.

Para la elaboración del presente artículo de investigación, vamos a tomar como base documental preferente la causa militar instruida al efecto. No obstante, también se ha consultado el Archivo Histórico del Partido Comunista de España (AHPCE) y la extensa bibliografía existente sobre el jefe guerrillero protagonista ${ }^{6}$. Por tanto, el sumario número 137.443, legajo número 6.702, custodiado en el Archivo General e Histórico de Defensa (AGHD), se erige en la pieza fundamental en que ha de cimentarse la elaboración del presente trabajo. Además, adquiere

${ }^{4}$ AGHD, sumario n. ${ }^{\circ}$ 134.443, diligencia de inspección ocular del terreno, folio 2 vuelto.

5 El año 1946, sobre todo en la primavera y verano, resultó ser nefasto para el movimiento armado en la parte norte de Cáceres. En abril de ese año, tuvo lugar la desarticulación de las bases de Zarza de Granadilla. El 21 de julio se llevó a cabo la detención de varios enlaces en las poblaciones de Torrecilla de los Ángeles y Villanueva de la Sierra; la actuación fue emprendida por la Guardia Civil y como el mismo capitán instructor reconoce en el atestado fue posible por la delación: «Que en virtud de confidencia, he tenido conocimiento de que en dicho pueblo existían varios enlaces de los bandoleros de la sierra...» (AGHD, Sumario número 137.277, atestado instruido por la Guardia Civil, folio 2). También en agosto de ese año, debido a la actividad de los delatores, tuvo lugar el aniquilamiento de la partida de «Compadre» (AGHD, Sumario número 137.503).

${ }^{6}$ En el Servicio de Estudios Históricos de la Dirección General de la Guardia Civil (SEHGC) aparece un breve apunte sobre la muerte del Jefe guerrillero: «El día 31 de julio del año anteriormente expuesto [1946] y al sitio de «Peña Falcón», término de Serradilla, se logró dar muerte al destacado jefe de bandoleros «El Francés», autor de múltiples asesinatos y fechorías, ocupándosele un fusil checo y una pistola reglamentaria del Cuerpo». SEHGC, Trabajos preparatorios para la elaboración de la Historia de la Guardia Civil en lo que afecta a la 106 Comandancia, p. 10. 
una importancia primordial en la investigación por no haber sido señalado en ninguno de los abundantes trabajos realizados sobre «El Francés». Precisamente, esta originalidad le confiere un plus de aporte a la investigación de la lucha guerrillera en general. A pesar de lo dicho, ha de tenerse en cuenta que, al tratarse de un documento elaborado por las autoridades militares franquistas, adolece de la imparcialidad deseada por ser parte en el asunto que nos atañe. Obviamente, la Guardia Civil y la judicatura del Régimen, esta última representada en el caso que nos ocupa por el Juzgado Especial de Espionaje y Comunismo, encarnan una posición diametralmente contraria al conjunto de la resistencia armada contra Franco. Así pues, es preciso obrar con la cautela debida en aras de conseguir la mayor objetividad. Por otra parte, la minuciosidad típica de la administración militar aporta un sinfín de detalles interesantes para la investigación.

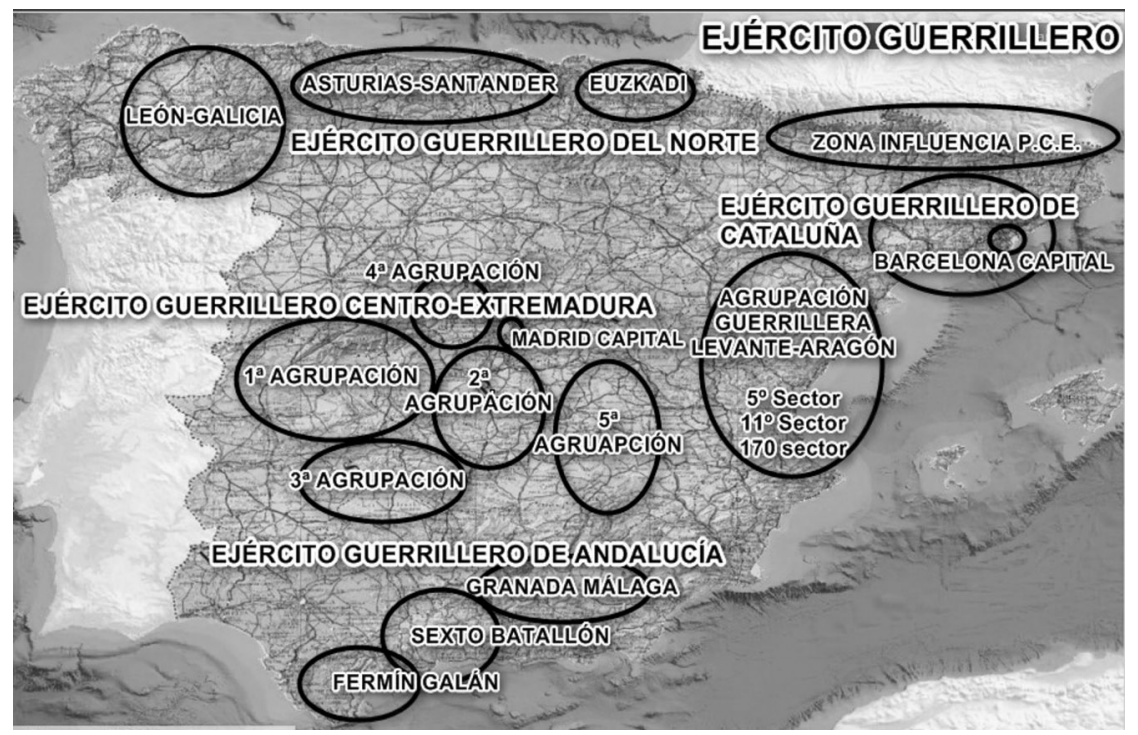

\section{Mapa 1}

Despliegue peninsular del Ejército Guerrillero

Fuente: Elaboración propia sobre un mapa del Instituto Geográfico Nacional. Fuente:

Archivo Histórico del Partido Comunista de España. 
El Archivo Histórico del PCE, profusamente consultado por la bibliografía consagrada al movimiento guerrillero contra el Dictador, resulta fundamental para el estudio de la misma. La documentación relativa a la organización guerrillera, la creación de las distintas Agrupaciones y otras directrices y ordenanzas para el desarrollo de la lucha armada, han sido de gran provecho para la investigación llevada a cabo. Igualmente valiosas son las numerosas instrucciones dadas por algunas Comandancias de la Guardia Civil custodias en este archivo; pues, teniendo en cuenta que dicha institución llevó el peso de la lucha contra el maquis, las circulares de sus jefes para combatir el «problema del Bandolerismo» ${ }^{7}$ constituyen una fuente de primer orden en los hechos examinados. Aunque la documentación referida a «El Francés» es más bien escasa, algunas registros como una carta dirigida al dirigente Jesús Bayón «Carlos», aportan una importante visión para el análisis de las operaciones guerrilleras. No obstante, en lo que se refiere a su muerte, argumento principal del presente trabajo, solamente hemos encontrado un breve apunte entresacado de la Reseña General del Problema de Bandolerismo elaborado por la Guardia Civil ${ }^{8}$.

Como he dicho, son muy abundantes las obras referidas a Pedro José Marquino alias «El Francés», pero ninguna de ellas señala entre sus fuentes el sumario analizado. La profusión de autores hace prácticamente imposible un estudio completo de sus escritos; por consiguiente, se han consultado aquellos de mayor peso en el asunto que nos atañe ${ }^{9}$. También es conveniente anotar las discrepancias, en algunos casos de cierto calado, con respecto a la causa jurídico-militar examinada. En un capítulo para ese cometido, se razonarán aquellas más significativas.

7 En el entorno franquista resultaba rara la denominación de guerrilleros o maquis, los apelativos más frecuentes eran los de bandoleros, forajidos o simples malhechores, obviamente querían desligar del fenómeno toda referencia que indicara su matiz político y reivindicativo de un régimen: el republicano, legalmente establecido y truncado por una sublevación militar.

8 AHPCE, caja 105, carpeta 3/3. El problema del bandolerismo en España después de la Guerra de Liberación, año 1946, Comandancia de Cáceres, p. 17: «El 31 de julio y tras incesante labor preparatoria inteligentemente se consiguió atraer al sitio conocido como «Peña Falcón» del término de Serradilla al jefe de varias partidas de bandoleros conocido por «El Francés», en dicho lugar se encontraba apostado un grupo de fuerza el cual al presentarse el bandolero le conminó a entregarse respondiendo con fuego de pistola y arma larga, por lo que repelida la agresión se consiguió darle muerte. Este bandolero dirigió el ataque al pueblo de Mesas de Ibor donde murió un guardia y era asimismo autor de los asesinatos cometidos en el pueblo de Los Santos (Salamanca)».

${ }^{9}$ Ver bibliografía. 


\begin{tabular}{|c|c|}
\hline \multicolumn{2}{|r|}{ EJÉRCITO NACIONAL GUERRILLERO } \\
\hline \multicolumn{2}{|r|}{ EJÉRCITO GUERRILLERO DEL CENTRO } \\
\hline \multicolumn{2}{|r|}{ JOSÉ ISASA "Fermín", PEDRO SANZ "Paco el Catalán" } \\
\hline AGRUPACIÓN & MANDOS \\
\hline EXTREMADURA & JESÚS BAYÓN "Carlos" \\
\hline GREDOS & FERNANDO GOMEZ "Colina" \\
\hline TOLEDO & JOSÉ MANZANERO, HONORIO MOLINA "Comandante Honorio" \\
\hline CIUDAD REAL & RAMÓN GUERREIRO “Julio", NORBERTO CASTILLEJO "Veneno" \\
\hline LA MANCHA-ALBACETE & ALFONSO ORTIZ "Vicente" \\
\hline MADRID & CELESTINO URIARTE, JOSE VITINI, CRISTINO GARCIA \\
\hline CORDOBA & DIONISIO TELLADO ${ }^{a}$ Ángel ${ }^{*}$ \\
\hline \multicolumn{2}{|r|}{ EJĖRCITO GUERRILLERO DE ANDALUCIA } \\
\hline \multicolumn{2}{|r|}{ RICARDO BENEYTO } \\
\hline AGRUPACIÓN & MANDOS \\
\hline MÁLAGA & RAMON VIA \\
\hline GRANADA & RAMIRO FUENTES OCHOS, JOSE MEREDIZ "Tarbes" \\
\hline JAÉN & TOMÁS VILLĖN "Cencerro" \\
\hline FERMIN GALĀN & BERNABÉ LÓPEZ CALLE, PABLO PÉREZ "Manolo el Rubio" \\
\hline \multicolumn{2}{|r|}{ EJÉRCITO GUERRILLERO DEL NORTE } \\
\hline AGRUPACION & MANDOS \\
\hline ASTURIAS & CONSTANTINO ZAPICO "Bógec" \\
\hline SANTANDER & CEFERINO ROIZ "Machado" \\
\hline EUZKADI & VITORIO VICUÑA "Julio Oria" \\
\hline \multicolumn{2}{|r|}{ FEDERACIÓN DE GUERRILLAS LEÓN-GALICIA } \\
\hline \multicolumn{2}{|r|}{ MARCELINO FERNÁNDEZ "Gafas" } \\
\hline I AGRUPACION & CESAR RIOS \\
\hline II AGRUPACION & MARIO MORÁN \\
\hline III AGRUPACIÓN & MANUEL CASTRO \\
\hline \multicolumn{2}{|r|}{ EJÉRCITO GUERRILLERO DE GALICIA } \\
\hline \multicolumn{2}{|r|}{ MARCELINO RODRIGUEZ "Marcofer" } \\
\hline III AGRUPACIONN LUGO & JOSE CASTRO "Piloto" \\
\hline IV AGRUPACIÓN CORUÑA & MARCELINO RODRIGUEZ "Marcoferc" \\
\hline \multicolumn{2}{|r|}{ AGRUPACIÓN GUERRILLERA DE LEVANTE } \\
\hline \multicolumn{2}{|r|}{ ÄNGEL FUERTES "Antonio" } \\
\hline $5^{\circ} \mathrm{SECTOR}$ & ATANASIO SERRANO "Capitán" \\
\hline $11^{\circ} \mathrm{SECTOR}$ & FLORIAN GARCIA "Grande" \\
\hline $17^{\circ}$ SECTOR & GERMĀN AMORROTU "Manso" \\
\hline \multicolumn{2}{|r|}{ AGRUPACIÓN GUERRILLERA DE CATALUÑA } \\
\hline & JOSEPH BRU, PEDRO VALVERDE \\
\hline
\end{tabular}

\section{Cuadro 1}

Composición del Ejército Guerrillero

Elaboración propia.

Fuente: ORTIZ MATEOS, A. http://lahistoriaenlamemoria.blogspot.com 


\section{Desarrollo y análisis del sumario incoado por la muerte de «El Francés»}

La causa número 137.443 , legajo 6.702, fue instruida a instancias de la muerte de Pedro José Marquino, ocurrida tras un enfrentamiento con la Guardia Civil en el término municipal de Serradilla el día 31 de julio de 1946. Como señala el Juez Especial para los delitos de Espionaje y Comunismo de la 1. a Región Militar, el expediente se inició a consecuencia de las:

Diligencias de carácter urgentes instruidas por el Capitán de la Guardia Civil D. José Vicente Herrero de la 6. ${ }^{a}$ Compañía de la $106 .{ }^{a}$ Comandancia ${ }^{10}$, con motivo del encuentro sostenido entre Fuerzas del Puesto de Serradilla (Cáceres) y rebeldes, en Peña Falcón del término de dicha localidad, en el que resultó muerto el Jefe de Bandoleros llamado Pedro y más conocido por el apodo de «El Francés» ${ }^{11}$.

Así es como lo contempla el certificado del citado capitán que dio curso a los hechos:

CERTIFICO: Que hallándome en la residencia de este puesto de Serradilla de mi demarcación, sobre las 10,30 horas de este día se presenta ante mí el Cabo Comandante del mismo Jesús Martín Caldera, dándome cuenta que a las 2,30 horas de hoy fuerza del puesto de Serradilla en servicio de emboscada en sitio denominado Peña Falcón, sostuvo encuentro con bandoleros de la sierra capturando muerto al Jefe de una División apodado (a) «Francés» con armamento, documentación y dinero; acto seguido me constituí en Juez Instructor para evacuar las diligencias de carácter urgente que determina el artículo 523 del vigente código de Justicia Militar, acompañado del Guardia 2. Julián López Sánchez, para que me auxilio como Secretario en la práctica de las diligencias que principio a instruir, cuyo individuo, interrogado convenientemente, acepta el cargo prometiendo cumplir bien y fielmente su cometido.

${ }^{10}$ Dentro del organigrama desplegado por la Guardia Civil, la 106. ${ }^{\text {a }}$ Comandancia pertenecía a la provincia de Cáceres, siendo la $6 .{ }^{a}$ Compañía con sede en Plasencia la unidad que abarcaba la demarcación del Puesto de Serradilla.

${ }^{11}$ AGHD, sumario n. ${ }^{\circ}$ 137.443, Diligencia de Enrique Eymar, Juez Especial para los delitos de Espionaje y Comunismo de la 1. ${ }^{a}$ Región Militar, folio 20. 
Y para que conste, lo firma conmigo en Serradilla a los treinta y un días del mes de julio de mil novecientos cuarenta y seis ${ }^{12}$.

El documento inmediatamente antes señalado aporta información importante para el presente artículo. Además de la hora y el lugar en que se produjeron los hechos, nos indica la estrategia de actuación de la Guardia Civil: en servicio de emboscada. Cuestión esta última interesante, pues la forma dispuesta por la fuerza policial ya aventura el conocimiento previo que habían de tener para actuar de tal modo y, por tanto, nos hace pensar con bastante verosimilitud en algún tipo de chivatazo o traición. Más adelante abordaremos en profundidad esta cuestión, intentando esclarecer los motivos de tal estrategia.

El mismo folio 2 del sumario recoge la providencia del Juez comunicando el traslado al lugar de los hechos y la notificación al Alcalde de la población para que se persone el médico titular de la Villa a fin de proceder al levantamiento del cadáver. También solicita del edil en cuestión los medios para trasladar dicho cadáver. A continuación dispone la constitución del juzgado en el aquel sitio y el levantamiento del cadáver con heridas de bala y metralla responsables «de la muerte instantánea».

El folio 2 vuelto contiene las «Diligencias de inspección ocular del terreno». Se trata de un apartado importante en el que se detalla con precisión la zona en la que tuvo lugar la emboscada y el tiroteo que causaron la muerte del jefe guerrillero. También recoge minuciosamente el modus operandi de los miembros de la Benemérita. Así viene señalado en el documento elaborado para ese cometido:

En la umbría de Peñafalcón del término municipal de Serradilla, hay en este sitio muy cerca del lomo que forma la sierra, el sitio denominado «Riscos del Pelao» enclavado en la misma vertiente de la cúspide, más para abajo hay una especie de plata-forma o toral que es el sitio donde ocurrieron los hechos, ambos lados de citada plata-forma hay unos montículos de piedra y por el centro de la misma partiendo de la umbría para la solana atravesando la sierra, viene una trocha que es la que traía el hombre muerto. La fuerza se hallaba situada en servicio de emboscada vigilando citada trocha, que es el paso frecuente que según los datos que la fuerza tenía, eran los que comunicaban

12 AGHD, sumario n. ${ }^{\circ}$ 137.443, Certificado del capitán instructor, folio 2. 
esta zona con Valeros, Corchuelas y las Cansinas del lado del Tietar y también las sierras del Guijo. Se hallaban apostados detrás de ambos montículos a la misma altura en tres grupos, al Norte se encontraba el Cabo 1. Jesús Martín Calera y Guardia 2. ${ }^{a}$ Fernando Canelo Rodríguez, al Este Guardias 2. ${ }^{\circ}$ Sergio García Sánchez y Antonio Fernández Garrido y al Oeste Guardias 2. ${ }^{\circ}$ Félix Redondo Bernal y Carlos Rey Pampín; el hombre muerto que al deducir de la documentación recogida es el llamado Pedro (a) «Francés», sin conocer sus apellidos, venía por una trocha que hay en citados riscos en el lugar del suceso. Al fondo de la citada sierra está por la parte Norte el «Arroyo Barbaón» y por la parte Sur una finca poblada de alcornoques propiedad de un tal Ángel Mateos (a) «Bermellao». Le fueron dados los altos reglamentarios sin obedecer a la llamada de la fuerza haciéndole fuego ambos grupos Norte y Oeste en principio y más tarde el que estaba situado en el Este, de cuyos disparos sobrevino la muerte según parte facultativo de reconocimiento y levantamiento de cadáver que obra anteriormente ${ }^{13}$.

De la diligencia antes expuesta se pueden extraer consecuencias reveladoras. Además de la ubicación pormenorizada del lugar ${ }^{14}$, se nos antoja significativa la forma de actuación de la fuerza policial. Según detalla el expediente militar, estaban bien parapetados y apostados a la espera de alguna incidencia. En definitiva, como especifica el capitán instructor: «en servicio de emboscada». Seguramente, se había preparado una emboscada porque había indicios suficientes para desarrollar tal estratagema. Esta cuestión nos avoca irremediablemente a la existencia de algún chivatazo que pusiera en alerta a la Guardia Civil. Así lo apuntan muchos de los autores estudiados, pero existen discrepancias a la hora de establecer el origen de la delación. La cuestión se debate entre dos corrientes: una la que apunta a un enlace de Cabezabellosa (Cáceres), Eusebio o Eugenio Montero; y la otra, aquella que acusa a dos guerrilleros renegados, Lucio Sánchez «El Lucio» y Gerardo Cano Monforte «Filfa» (también apodado «Panza Alegre»y «El Pesca»), de quienes se decía que habían reci-

13 AGHD, sumario n. ${ }^{\circ}$ 137.443, Diligencia de inspección ocular del terreno, folio 4 vuelto.

14 Área acotada al norte de la sierra de Peñafalcón, entre los arroyos Barbaón y Barbaoncillo, próximos a la confluencia de los ríos Tajo y Tiétar, en el término municipal de Serradilla (Cáceres). Actualmente esta zona está encuadrada en la parte más occidental del Parque Natural de Monfragüe. 
bido treinta mil pesetas por el chivatazo ${ }^{15}$. En consecuencia, no podemos apuntar al respecto una identificación clara.

Dejando de lado el origen de la confidencia, lo interesante para la investigación es la presencia de un grupo de la Guardia Civil camuflados en las proximidades de la estafeta guerrillera para atacar a los componentes de la partida que habían de acercase a la misma. Tal y como señala el atestado, el servicio de vigilancia contra la guerrilla se llevaba montando desde pocos días atrás. A pesar de parecer admisible la delación de algunos de los guerrilleros entregados a la fuerza policial, no debemos soslayar en modo alguno la nueva estrategia de la Benemérita en la persecución de «bandoleros». Así, las instrucciones del teniente coronel Eulogio Limia Pérez ${ }^{16}$, uno de los mayores beligerantes contra el movimiento de resistencia armada antifranquista, resultan esclarecedoras en el modus operandi aplicado al hecho analizado, independientemente del origen de la confidencia y hasta de si la misma tuvo lugar. Efectivamente, Limia recogía en su «Orden Especial número 2 sobre servicio de bandolerismo», toda una batería de medidas de actuación dirigidas a las Contrapartidas, Patrullas Auxiliares, Grupos Móviles y demás unidades de la Guardia Civil que operaran en las zonas habituales del maquis. Entre otras las siguientes:

\section{SERVICIO DE OBSERVACIÓN DIURNA, CORRERÍAS Y APOSTADERO NOCTURNO.}

Todos los Puesto y Destacamentos que se ordene por esta Jefatura, nombrarán por el tiempo de cuatro días una patrulla de cuatro hombres si tienen fuerza superior a siete y de tres si su fuerza es de siete o menos, que saldrá al romper el día practicando servicio de correría y reconocimiento de puntos sospechosos del terreno en el itinerario que se le haya señalado en papeleta, cuyo servicio se practicará hasta las trece horas en que la patrulla se retirará al cortijo que también se le señale para confeccionar la comida y descansar, saliendo nuevamente a las quince horas en invierno y a las diez y siete en verano para si-

\footnotetext{
${ }^{15}$ Castro, 2016, p. 441; Chaves, 2005, pp. 154 y 155; Díaz, 2011, p. 428: Moreno, 2001, p. 395.

16 Este oficial superior de la Benemérita estuvo encargado de la represión del «bandolerismo» en la zona centro del país cuando actuó como jefe del Sector de Huidos y, posteriormente, también durante su etapa como jefe de la Comandancia de Granada.
} 
tuarse en observación en el cerro o altura designada en papeleta a la que procurarán llegar por la parte opuesta a la zona que haya de ser vigilada y si no fuera posible, aprovechando la maleza, barrancos $\mathrm{u}$ otros accidentes del terreno para no ser vistos tanto por los bandoleros como por el elemento civil, cuya observación se practicará sobre cortijos, zonas del monte que sean paso de bandoleros o majadas de pastores y sus rebaños, albergues de carboneros y tajos donde trabajan, observando tanto los movimientos de este personal, como los de todos los que transiten por el campo, levantando la observación antes de la noche en forma que llegue la patrulla a un cortijo cualquiera que también, se señalará en papeleta, precisamente al anochecer, en el cual permanecerán hasta que la visibilidad sea nula, en cuyo momento haciendo contramarcha se dirigirán a otro cortijo que igualmente se señalarán y una vez llegado al mismo, después de prevenir a sus moradores, montarán servicio de apostadero fuera del cortijo hasta la hora en que se acostumbre a cerrar las puertas sin que pueda exceder de las veinticuatro en verano ni de las veintidós en invierno, retirándose después a descansar en el interior del cortijo. Al amanecer del día siguiente, saldrá nuevamente la patrulla para verificar análogo servicio que el día anterior, (correrías y reconocimiento hasta las trece, por la tarde observación y por la noche contramarcha y apostadero en otro cortijo) y así sucesivamente durante tres días, retirándose al Puesto o Destacamento en la mañana del cuarto día para salir otra patrulla al amanecer del día siguiente también por cuatro días y con análogo servicio que la anterior ${ }^{17}$.

Como vemos, el documento expuesto nos muestra una ordenanza policial perfectamente aplicable al asunto que nos atañe. La declaración del cabo primero Comandante del Puesto de Serradilla, incluida en el folio 6 vuelto del atestado, no hace sino confirmar la operativa del grupo emboscado:

Que con motivo de servicio propio del Cuerpo en la persecución de bandoleros ordenado por la Superioridad periódicamente establecía servicios de emboscada en los sitios estratégicos por donde se suponía fueran pasos frecuentados por los bandoleros. El día 29, 30 y 31, acordé fuese practicado este servicio en el sitio denominado «Peñafalcón» de la demarcación de este puesto, montando el servi-

17 AHPCE, Caja 106, carpeta 1/1, Documentos Guardia Civil, 136 Comandancia (Granada), Orden especial número 2 sobre servicio de bandolerismo. 
cio de emboscada durante la noche y el de observación durante el diurno... ${ }^{18}$.

La disposición de la fuerza atacante, según muestra el atestado policial, despeja cualquier duda sobre la intención de los miembros de la Benemérita. Parapetados detrás de unos montículos y riscos de piedra se dividieron en tres grupos de dos guardias civiles cada uno, entre ellos el Comandante del Puesto, con el propósito de capturar, con el menor riesgo, a los guerrilleros que accedieran por el camino hacia la estafeta. Así ocurrió en las primeras horas del día 31 de julio de 1946 cuando sintiendo la presencia de «El Francés», y después de no responder a los «altos reglamentarios», todos los grupos descargaron abundantemente sus armas, incluso con el lanzamiento de una bomba de mano, acribillando al jefe guerrillero. La dinámica detallada de los acontecimientos viene recogida en la declaración del jefe de los emboscados:

... sintieron pasos de persona que no pudieron distinguir dada la oscuridad de la noche, pero en unas rocas por encima del plano o plataforma en que ellos se encontraban, buscaba algo que no encontraba y la indignación que esto le producía le desató la ira blasfemando encolerizado porque al parecer no lograba sus propósitos. Ya cansado de buscar sin alcanzar sus deseos, decide marcharse; en cuya actitud y viendo el declarante que citado sujeto se marchaba una vez evacuados sus propósitos y que nadie más se sentía ni de cerca ni de lejos que le acompañase, le hecho (echó) el alto reglamentario de, quien vive, contestando con fuego de pistola hacia el lugar donde se le hecho (echó) el alto, momento en el cual el declarante repelió la agresión haciendo uso de su arma y ordenando a la fuerza hiciese fuego contra citado individuo, éste al verse cogido entre dos fuegos de frente y flanco se parapetó detrás de unos riscos haciendo fuego de fusil sobre la fuerza, visto lo cual el declarante, mientras las dos parejas situadas a Este y Oeste sostenían el fuego llamándole la atención para ver si se entregaba, el declarante avanzó en unión del guardia Fernando Canelo Rodríguez, a uno de los costados del bandolero instándole a que se entregase, y como contestara negativamente a pesar de la insistencia que se le hizo disparando su fusil sobre al fuerza, se le hicieron nuevas descargas por el declarante siendo alcanzado por varios disparos

18 AGHD, sumario n. ${ }^{\circ}$ 137.443, Declaración del cabo $1 .^{\circ}$ Comandante del Puesto de Serradilla, folio 6 vuelto. 
de subfusil, cayendo a tierra el mismo tiempo que el guardia Fernando Canelo Rodríguez le lanzó una bomba de mano produciendo todo ello la muerte instantánea ${ }^{19}$.

Si nos atenemos a esta declaración, parece probable la muerte inmediata por los efectos de los numerosos disparos realizados y la bomba de mano lanzada por uno de los guardias. Del mismo modo, la autopsia practicada por los médicos titulares de la localidad diagnostica la muerte instantánea de «El Francés» por las diversas heridas encontradas «y muy especialmente producida por la destrucción de la masa encefálica $»^{20}$. La causa de la muerte también queda reflejada en el escrito confeccionado por el capitán instructor y dirigido al coronel Eymar, Juez Especial para los Delitos de Espionaje y Comunismo: «... la muerte sobrevino por varios impactos que se le aprecian en la cabeza, pecho y quemaduras en las piernas y vientre por efectos de una bomba de mano ${ }^{21}$. Aunque tras lo expuesto no parece haber lugar para la duda, esta cuestión alimenta algún tipo de controversia en la bibliografía estudiada. Incluso algunos autores no descartan la muerte del guerrillero por la pérdida de sangre al permanecer toda la noche herido y sin ser auxiliado por la Guardia Civil, a pesar de haber solicitado ayuda en varias ocasiones.

En el siguiente apartado, el dedicado a las discrepancias entre las fuentes, intentaremos esclarecer ésta y otras cuestiones. Sobre este asunto, también aporta cierta confusión el acta de defunción realizada por el Juez de Paz de Serradilla al señalar el fallecimiento «a consecuencia de Traumatismo» ${ }^{22}$. Argumento que recogen algunos autores y que, igualmente, explicitaremos en el apartado señalado.

La abundancia de disparos que acabaron con la vida del jefe guerrillero parece también confirmarse por los desperfectos producidos en las armas que portaba el maquis. De tal guisa lo recoge la causa militar:

... el armamento que llevaba se componía de un mosquetón «Checo» número 4374-H.3, Pistola «Star» número 41563 con setenta y cuatro cartucho de mosquetón y un cargador completo de la pistola, así

\footnotetext{
${ }^{19}$ AGHD, sumario n. ${ }^{\circ} 137.443$, declaración del cabo primero Comandante del Puesto de Serradilla, folio 6 vuelto.

${ }^{20}$ AGHD, sumario n. ${ }^{\circ} 137.443$, diligencia de autopsia, folios 3 y 3 vuelto.

21 AGHD, sumario n. ${ }^{\circ} 137.443$, escrito del Instructor remitido al Juez Especial de los Delitos de Espionaje y Comunismo de la 1. ${ }^{\text {a }}$ Región Militar, folio 10.

${ }^{22}$ AGHD, sumario n. ${ }^{\circ}$ 137.443, certificación literal del acta de defunción, folio 6 .
} 
como también una bomba de mecha de las llamadas «Petardos», tanto el estado del mosquetón como el de la pistola, se hallan inutilizados por efecto de los disparos hechos por la fuerza... ${ }^{23}$.

Obviamente, si las dos armas quedaron en tal estado se debió a un intenso tiroteo; pues, si se hubieran producidos escasos disparos, sería poco probable causar tales desperfectos.

Sobre este armamento, tanto el escrito del capitán instructor como la exposición al Tribunal del Juez Eymar aportan algunas precisiones al respecto, como el calibre de la pistola, el número de balas halladas en el cargador o la clasificación de la cartuchería del fusil ${ }^{24}$; cuestiones en todo caso de menor importancia para la investigación.

También resulta interesante, aunque no venga detallada en el sumario, la documentación que tenía el jefe de la 12 . ${ }^{a}$ División y que fue remitida al Puesto de Mando de Navalmoral de la Mata (Cáceres). No debemos olvidar el inconveniente que las anotaciones encontradas en el cadáver ocasionarían a la guerrilla. Resulta fácil imaginar el trastorno que había de causar en los guerrilleros y sus colaboradores una información tan sensible en manos de las fuerzas represoras, máxime en este caso al tratarse de un jefe guerrillero. Probablemente, la documentación custodiada por «El Francés» contaría con nombres de guerrilleros y enlaces, familias amigas, ubicación de campamentos, partidas guerrilleras, etc. Seguramente, el solo conocimiento de su muerte, además del dramatismo que conlleva y la pérdida de un líder guerrillero, removerían los cimientos de apoyo al maquis. Los mandos de la Guardia Civil del Sector de Huidos de la zona centro del país se congratularían de tales hallazgos. Las presiones y torturas a las personas identificadas y sus familiares alimentarían las traiciones. Así, como si de un frágil castillo de naipes se tratara, la estructura de apoyo a la guerrilla se derrumbaría sin remedio hasta desembocar en su aciago final.

Existe otro punto confusamente tratado en el sumario: - «El Francés» ¿venía sólo o acompañado para revisar la estafeta? Ciertamente, en el encuentro de Peñafalcón, la Guardia Civil detecta la llegada por el camino vigilado de un solo hombre. La refriega tuvo como protagonis-

23 AGHD, sumario n. ${ }^{\circ}$ 137.443, diligencia de reconocimiento del cadáver, folio 3 .

${ }^{24}$ AGHD, sumario n. ${ }^{\circ} 137.443$, declaración del capitán instructor, folio 6 y escrito de exposición del Juez Especial de los Delitos de Espionaje y Comunismo de la 1. ${ }^{\text {a Región }}$ Militar, folio 20. 
tas al grupo de guardias emboscados y al jefe guerrillero, sin mención a ningún otro partícipe. Por tanto, está claro que el enfrentamiento se entabló entre las dos partes señaladas. Igualmente, tanto las declaraciones del cabo primero de la Guardia Civil como las del capitán instructor, detectan la presencia de un «bandolero» en el lugar de los hechos. Incluso, el último de los mencionados va más lejos aún cuando indica que, tras dar el «alto reglamentario», se inició el tiroteo al comprobar «que citado sujeto se marchaba una vez evacuados sus propósitos y que nadie más se sentía ni de cerca ni de lejos ${ }^{25}$. Sin embargo, el coronel Juez Especial de los Delitos de Espionaje y Comunismo, en su escrito de exposición de los hechos remitido al Tribunal Militar, contempla la existencia en las cercanías de la refriega de dos escopetas y un puñal que posiblemente pertenecieran a los camaradas de «El Francés». Así viene recogido en el citado documento: «Al continuar la fuerza los reconocimientos por los lugares cercanos, se encontraron dos escopetas cargadas que sin duda debieron pertenecer a los bandoleros que escoltaban al «Francés» y que al oír los disparos debieron huir; y un puñal de construcción casera» $^{26}$.

De lo expuesto, podemos apuntar que el enfrentamiento tuvo lugar únicamente entre el grupo de guardias civiles y el jefe guerrillero que resultó muerto; sin embargo, las armas encontradas abandonadas en las proximidades sugieren la presencia de algunos guerrilleros que acompañarían a «El Francés», permaneciendo a una distancia prudencial mientras éste se acercaba a la estafeta. La bibliografía propuesta tampoco se pone de acuerdo en este asunto. Las distintas versiones existentes serán concretadas en el próximo capítulo.

Termina la instrucción policial con una providencia del Juez, fechada el 1 de julio de 1946, es decir un día después de ocurrir los hechos, en la que da cuenta de haber recibido en el juzgado diversa documentación para su archivo. Entre otras, la licencia de enterramiento y reseña del lugar que ocupa en el cementerio de la población, el acta de inscripción en el Registro Civil y un «oficio del Sr. Cura Párroco de Serradilla de haber prestado los auxilios espirituales al cadáver» ${ }^{27}$.

25 AGHD, sumario n. ${ }^{\circ} 137.443$, declaración del capitán instructor, folio 6.

26 AGHD, sumario n. ${ }^{\circ} 137.443$, escrito de exposición del Juez Especial de los Delitos de Espionaje y Comunismo de la 1. ${ }^{\text {a }}$ Región Militar, folio 20.

27 AGHD, sumario n. ${ }^{\circ}$ 137.443, providencia del Señor Juez, folio 3 vuelto. 


\section{Discrepancias entre el sumario analizado y la bibliografía consultada}

A continuación, vamos a considerar algunas versiones contrapuestas entre el sumario analizado y la bibliografía estudiada; incluso, en ciertos casos, las contradicciones existentes entre los autores consultados. En modo alguno nos proponemos realizar un trabajo exhaustivo sobre el asunto, entre otras cosas, porque escaparía a la pretensión del artículo presente. Más bien, ha de entenderse como un ejercicio ponderado encaminado a encontrar la mayor verosimilitud posible dentro de las distintas fuentes contrastadas. Tampoco se pretende otorgar el beneficio de la veracidad absoluta a la causa militar estudiada; pues, como advertimos en la introducción, al ser parte interesada, carece de imparcialidad. La cuestión se ha de enfocar desde una óptica de posibilidades, de aplicar cierta lógica a las distintas posturas, algunas tan dispares que circulan por sentidos contrarios. En definitiva, realizar una labor de rigurosa disección que nos permita distinguir, o al menos entrever, la verdad de los acontecimientos aquí narrados.

La primera cuestión al respecto apunta a la existencia de algún tipo de chivatazo o delación que permitiera a la Guardia Civil establecer el servicio de emboscada para interceptar a los guerrilleros de la zona. Así parece confirmarlo la diligencia del cabo Comandante del Puesto de Serradilla cuando anota lo siguiente: «La fuerza se hallaba en servicio de emboscada vigilando citada trocha, que es el paso frecuente que según los datos que la fuerza tenía, eran los que comunicaban esta zona con Valeros, Corchuelas y las Cansinas del lado del Tiétar y también la sierra del Guijo» ${ }^{28}$.

Parece claro que las fuerzas policiales disponían de una información precisa que propició el establecimiento del operativo en esa zona concreta. Ahora bien, a través del sumario analizado no se puede concretar como habían conseguido esa confidencia tan sensible y acertada. Según la bibliografía estudiada, todo parece apuntar a una acusación proveniente del entorno guerrillero. Julián Chaves ${ }^{29}$ y Benito Díaz ${ }^{30}$ así lo establecen en sus obras, aunque les resulta difícil identificar a los responsables. Francisco Moreno, siguiendo el testimonio del guerrillero «Pinto» también apunta al soplo, pero no reconoce su origen: «A raíz de una deserción

\footnotetext{
28 AGHD, sumario n. ${ }^{\circ} 137.443$, diligencia de inspección ocular, folio 2 vuelto.

${ }^{29}$ Chaves, 2005, pp. 153 y 154.

30 Díaz, 2011, p. 428.
} 
en el mes de abril, que no parece bien identificada en el testimonio de «Pinto», esa estafeta quedó delatada y quemada» ${ }^{31}$. En análoga forma lo recoge Ángel Prieto, pero discrepa del sumario en la noche del suceso ${ }^{32}$ :

En cada paso, en cada camino, se emboscaba la Guardia Civil esperando la más mínima oportunidad para acabar con el mítico guerrillero y ésta se le presentó la noche del 30 al 31 de julio en la Umbría de Peñafalcón (Serradilla), cuando acompañado, entre otros por Jerónimo Iglesias Prieto «Relojero», se dirigía a recoger información en una estafeta que habían quemado Lucio Sánchez «Lucio», natural de Valdeverdeja (Toledo), y Gerardo Cano Monforte «El Pesca» de Serrejón, por una gratificación de 30.000 pesetas. Esta información no es segura, porque tiempo después un «Belloso» que tuvo sus cabras bastantes años en el majar de Conejeros le dijo al abuelo que el que había delatado al Francés fue un cabrero de Cabezabellosa llamado Eusebio o Eugenio Montero $\ll$ Liebre ${ }^{33}$.

Sin entrar en más detalles, podemos apuntar como colofón la coincidencia existente entre el expediente militar y la bibliografía consultada respecto de la información tan importante que la Guardia Civil tenía sobre la estafeta que había de visitar el jefe guerrillero. Sin poder precisar, en el caso del sumario porque no lo refleja y en la bibliografía por las dudas en su atribución, la identificación del origen de la misma; aunque parece plausible que partiera del entorno guerrillero.

Si bien no parece haber discrepancias sobre el despliegue de la fuerza policial para capturar a «El Francés», sí existen diferencias en cuanto al número de guardias civiles que la componían. El sumario, como se ha reflejado en el apartado anterior, recoge nítidamente la presencia de seis guardias civiles (cinco guardias bajo el mando de un cabo primero) divididos en tres grupos y apostados convenientemente en las inmediaciones de la estafeta guerrillera. Raimundo Castro cuenta cinco miembros de la Benemérita: «La prueba de que no esperaban al Francés a tiro fijo fue que solo controlaban el lugar de paso, desde un escondrijo, cuatro guardias y su cabo primero» ${ }^{34}$. Benito Díaz anota la presencia de «tres guardias civi-

31 Moreno, 2001, p. 395.

32 También Secundino Serrano fecha la muerte de «Francés» el 30 de julio de 1946, un día antes del señalado en el sumario. Serrano, 2001, p. 177.

33 Prieto, 2004, p. 136.

34 Castro, 2016,pp. 441 y 442. 
les que habían relevado a otros tres» ${ }^{35}$, por tanto en el enfrentamiento solamente participarían tres miembros de la Benemérita. Cuestión que contradice el atestado policial, aunque parece la versión más probable, porque para este tipo de servicio normalmente se ordenaría la constitución de una patrulla con un número mayor de guardias civiles que los tres señalados por el autor. Especialmente en este caso, pues se tenía información más o menos fiable de la presencia de guerrilleros por la zona vigilada.

Tampoco existe unanimidad en cuanto a la causa de su muerte. Algunas versiones apuntan a la pérdida de sangre por permanecer toda la noche herido sin ser atendido por los guardias civiles, a pesar de haber solicitado su ayuda en varias ocasiones. Así lo narra Ángel Prieto: «De cómo se produjo la muerte empezaron a circular distintas versiones que, como puedes suponer, diferían notablemente en función de quién las contaba. Para nosotros había muerto como un bravo guerrillero, pues cuando hallaron el cadáver, al día siguiente, desangrado, tenía un fusil ametrallador entre las manos y en posición de disparo. Para ellos, en cambio, murió pidiendo auxilio a la Guardia Civil» ${ }^{36}$.

También Benito Díaz alude al desfallecimiento mortal por la pérdida de sangre, tras las heridas provocadas por los disparos de la Guardia Civil: «... le dispararon, pero como era de noche, permanecieron ocultos hasta que por la mañana comprobaron que "El Francés" se había desangrado» ${ }^{37}$

Además, el acta de defunción señalando la muerte del guerrillero «a consecuencia de Traumatismo» ${ }^{38}$, parece haber levantado cierta suspicacia en algunas de las obras consultadas. Julián Chaves, en su libro sobre la vida del maquis Gerardo Antón «Pinto», apunta lo siguiente: «Sucedió este fatal desenlace, según consta en Libro de Defunciones del Registro Civil de Serradilla, donde se inscribió su fallecimiento dos semanas después, en la madrugada del 31 de julio de 1946 en la «Umbría de Peña Falcón», a consecuencia de «traumatismo». Sorprendente eufemismo el utilizado para señalar la causa de muerte, que no fue otra que los disparos de la Benemérita» ${ }^{39}$.

35 Benito DÍAZ, Huidos y guerrilleros..., pp., 427 y 428: «En las proximidades de la estafeta que estaba descubierta, se encontraban apostados tres guardias civiles, que hacía poco habían relevado a otros tres».

36 Ángel PRIETO, Guerrilleros de la libertad..., pp. 136 y 137.

37 Benito DÍAZ, Huidos y guerrilleros..., p. 428.

38 AGHD, sumario n. ${ }^{\circ} 137.443$, certificación literal del acta de defunción, folio 6.

39 Julián CHAVES, Guerrilla y Franquismo, p. 154. 
Es cierto que la causa de la muerte por traumatismo señalada en el acta de defunción avoca a la duda. Pero no es menos cierta la equivocación de la misma al advertir que así viene reflejado en la autopsia. Pues, como hemos visto en las páginas anteriores, la autopsia señala claramente la muerte instantánea del guerrillero por efecto de las heridas de bala y la bomba de mano. Sobre todo, tal y como manifestaron de común acuerdo los dos médicos que la practicaron, por la «destrucción de la masa encefálica». A continuación se transcribe literalmente la Diligencia de Autopsia recogida en la causa jurídico-militar:

En Serradilla a los Treinta y un días del mes de Julio de mil novecientos cuarenta y seis, el Señor Juez con asistencia de mí el Secretario, y citados al efecto comparecieran los Médico Titulares relacionados al margen, quienes juraron decir verdad en lo que supieren y fueran preguntados acerca de la misión que por orden del Sr. Juez han de practicar la autopsia en el cadáver del bandolero de la sierra muerto por fuerza del Cuerpo de la Guardia Civil en las primeras horas de hoy, manifestando de común acuerdo que: resulta ser un individuo de 32 a 35 años de edad, de estatura media, el cual presenta externas quemaduras en tórax y vientre; un orificio de entrada por arma de fuego en coronal con salida del occipital, dos heridas de la misma naturaleza en la región torácica con salida por la espinal y una antigua cicatriz en el tercio inferior de la pierna izquierda con pequeña desviación hacia fuera de la misma fractura.

Abierto el cráneo se observa interna hemorragia, perforación del occipital y una gran destrucción del hemisferio cerebral. Abierta la cavidad torácica se encuentran ambos pulmones perforados por sus bases. Nada anormal en la cavidad abdominal ni en las extremidades. De lo expuesto se deduce que la muerte ha sido instantánea y muy especialmente producida por la destrucción de la masa encefálica.

En vista de lo cual, el Señor Instructor dio por terminado dicho reconocimiento de autopsia, y leída que les fue esta declaración por mí el Secretario, la hallaron conforme y la firman en prueba de ello con el Señor Juez y Secretario que certifico ${ }^{40}$.

Al margen del documento se anota: «Diligencia de autopsia llevada a cabo por los Médicos titulares de esta localidad Don Julio Rivas Mateo y Don Francisco Hernández Hernández». Al final del escrito se estampan

${ }^{40}$ AGHD, sumario n..$^{\circ} 137.443$, diligencia de autopsia, folios 3 y 3 vuelto. 
legibles las firmas de los médicos y del Secretario Julián López Sánchez, resultando ilegible la del Juez Instructor.

Después de los argumentos anteriormente desarrollados, la tesis defendida en el sumario de una muerte instantánea parece la más verosímil. No sólo los numerosos disparos efectuados por los emboscados y la bomba de mano lanzada por el guardia Canelo parecen avalar ese razonamiento, también los daños producidos en el cuerpo del guerrillero por efecto de esa descarga tan brutal, y recogidos en la autopsia, corroboran tal aseveración. Bien es verdad que tanto los atestados instruidos por las fuerzas represoras como las certificaciones médicas, se ajustaban sin fisuras a las exigencias del Régimen. Pero en este caso, no atino a comprender una actuación comprometida en la narración de los hechos ni en la autopsia practicada para cambiar la versión de los mismos. Seguramente, unos guardias civiles advertidos y emboscados, cuando percibieron la presencia del jefe guerrillero, lo acribillaron sin más. Los médicos que practicaron la autopsia se limitaron a plasmar los destrozos ocasionados en el cadáver por efecto de la balacera.

Existe cierta controversia en relación al número de guerrilleros que acompañaban a «El Francés». El mismo sumario, como anotamos en el apartado anterior, no aclara escrupulosamente este asunto. Por una parte, la declaración del cabo primero jefe de los emboscados, admite la presentación de un solo individuo y no advirtió la presencia de más «bandoleros». Precisamente, la ausencia de otros guerrilleros unido a la posible marcha del protagonista, después de no encontrar nada en la estafeta revisada, inició el tiroteo que acabaría con su vida. Así lo contempla también la declaración del capitán instructor; quién, con toda probabilidad, se limitaría a recoger la información dada por su subordinado. Sin embargo, el escrito de exposición de los hechos dirigidos al Consejo de Guerra y confeccionado por el Juez Especial para los Delitos de Espionaje y Comunismo, en cierto modo, discrepa de las versiones anteriores. El citado documento observa la existencia de diverso armamento abandonado en las proximidades del lugar donde se produjo el tiroteo que causó la muerte de «El Francés». Ciertamente, el Juez da por hecho que pertenecía a los maquis acompañantes del jefe guerrillero. Sin embargo, no resulta claro explicar su abandono. El representante franquista lo achaca a una retirada precipitada tras oír los disparos de los guardias. Pero, tratándose de dos escopetas y un puñal, por tanto de fácil transporte, no acierto a entender tal imprudencia, máxime cuando se podrían utilizar en su defensa si llegara el caso. A no ser que cundiera el pánico entre sus portadores y optaran por una huida a matacaballo. 
La bibliografía tampoco se pone de acuerdo en este asunto. Francisco Moreno anota la llegada de tres guerrilleros a la zona, aunque solamente uno se enfrentó a los guardias: «En la noche del 30 al 31 de julio, se acercaron a Peña Falcón «El Francés», «Viruta» y «Abuelo». Una contrapartida les hacía la espera. A las dos de la madrugada apareció «El Francés» apareció solo. La contrapartida esperó a ver si venían más, pero como no aparecían, lo conminaron a la rendición. «Francés» dio un salto en busca de refugio y disparando, pero los guardia le ganaron la partida ${ }^{41}$.

Idéntica compañía recoge la obra consultada de Secundino Serrano: «El maquis más respetado y carismático de Extremadura, el cordobés Pedro Díaz Monje «Francés», jefe de la 12. ${ }^{a}$ División, había encontrado la muerte el 30 de julio de 1946 en la Umbría de Peña Falcón, en Serradilla, y posteriormente serán detenidos sus dos acompañantes, Amancio Nieto Calero «Abuelo» y Fausto Navas Navas «Viruta» ${ }^{42}$.

También Ángel Prieto señala en su libro la aparición de varios guerrilleros junto a «El Francés», aunque solamente identifica a uno de ellos: «... cuando acompañado, entre otros, por Jerónimo Iglesias Prieto, «Relojero», se dirigía a una estafeta...» ${ }^{43}$

Sin embargo, Benito Díaz manifiesta la presencia de un solo guerrillero, distinto a los señalados por Moreno y Serrano, y coincidente con el identificado por Prieto:

La 12. ${ }^{a}$ División quedará descabezada el 31 de julio al morir «El Francés» en una emboscada tendida por la Guardia Civil, cuando en unión de Jerónimo Iglesias Prieto «Relojero» iba a inspeccionar una estafeta situada en la sierra de Peña Falcón, en las proximidades de Serradilla. Esta estafeta servía para mantener el contacto con la partida liderada por «Calandrio». «Relojero se quedó atrás como precaución, por orden de «El Francés», que quiso acercarse solo ${ }^{44}$.

En términos parecidos se expresa Julián Chaves explicando la comparecencia de «Relojero» que permaneció rezagado y oculto en las cercanías por indicación de «El Francés». Por tanto, cuando ocurrió el tiroteo que acabó con la vida de su jefe, bien pudo ser el que huyera abandonando las ar-

${ }^{41}$ MORENO, F., La resistencia armada..., op. cit., p. 395.

42 SERRANO, S., Maquis..., op. cit., p. 177.

43 PRIETO, A., Guerrilleros de la libertad..., op. cit., p. 136.

${ }^{44}$ DÍAZ, B. Huidos y guerrilleros..., op. cit., p. 427. MORENO, F., La resistencia armada..., op. cit., p. 395. 
mas encontradas por la Guardia Civil y especificadas en el escrito del Juez Eymar, pero no es posible determinar con absoluta certeza que así ocurriera.

Como colofón y a raíz de lo expuesto, podemos establecer en esta cuestión dos proposiciones con suficientes visos de verosimilitud: 1) «El Francés» se personó en la zona con algún compañero de armas, pero resulta complicado identificar al acompañamiento, aunque lo más probable es que se tratara de «Relojero»; y 2) En el enfrentamiento con la Guardia Civil, por parte de la guerrilla antifranquista solamente intervino el jefe guerrillero que resultó muerto.

Aunque cuestión de menor importancia para el presente trabajo, también resulta contradictoria la versión existente sobre la actuación del guardia civil Fernando Canelo Rodríguez. Para algunos autores, ante los primeros disparos, salió corriendo hacia un puesto de barquero que hay en la desembocadura del arroyo Barbaón, perdiendo en la escapada una bota. Esta es una de las versiones que señala en sus páginas el blog Iusipedia:

Fuere como fuere lo cierto es que en la noche del 30 al 31 de julio de 1946 Pedro José Marquino Monje «El Francés» se hallaba en la Umbría de Peñafalcón (Cuarto de Entre Arroyos) de Serradilla, donde le dieron muerte, tras ser localizado por fuerzas de la Guardia Civil. Sobre las circunstancias en las que acaece la muerte de «El Francés» han existido versiones variadas, que resumimos del siguiente modo:

El encuentro se produce en una situación en que tano los guerrilleros como los guardias civiles estaban presos del miedo. Los maquis vieron primero a los guardias civiles, pero, aún teniéndolos a tiro, no dispararon al pensar que podía haber más Guardias Civiles (así lo informó «Durruti» en su detención llevada a cabo el mismo día). La sensación de los maquis es que estaban rodeados, algo que relativamente era cierto, pero por pocos número de la Benemérita, por lo que, de haberlo sabido, hubieran podido intentar la fuga. Al primer disparo el guardia civil Fernando Canelo salió huyendo en dirección a la barca de «peseta», en la desembocadura del arroyo Barbaón, perdiendo en su huida una bota que no volvió a buscar. En la refriega hubo cruce de disparos y algunas versiones apuntan que también se tiraron bombas de mano que produjeron un pequeño incendio ${ }^{45}$.

Así lo contempla también Raimundo Castro, refiriéndose a los guardias emboscados: «... se quedaron aterrorizados cuando llegó el jefe de

45 lusipedia.blogspot.com/2009/01/el-frances.htm. 
los proscritos porque pensaron que le acompañaría una docena de maquis. Por lo menos. Tanto miedo tuvieron que, cuando empezó el tiroteo, un guardia que se apellidaba Canelo salió corriendo en dirección a la barca de la peseta, la que había en la desembocadura del arroyo Barbaón para cruzare el río Tajo, y acabó perdiendo una bota a por la que nunca regresó ${ }^{46}$.

En este asunto parece más verosímil la versión de la Guardia Civil expuesta en el sumario. Además, fue el guardia que se encontraba junto al cabo y el que arrojó la bomba hacia la posición ocupada por «El Francés». Por tanto, no compartimos las versiones anteriores, aunque en el caso de Raimundo Castro pudiera tratarse de una licencia generada por la versión novelada de los hechos.

Por último, y como hemos visto a lo largo del trabajo expuesto, existen pequeñas desviaciones en la cronología exacta de los hechos. Las variaciones consisten en ubicarlo temporalmente en tres momentos: por una parte, aquella que lo data el 30 de julio de 1946 sin mayores especificaciones ${ }^{47}$; por otro lado, los autores que inscriben los acontecimientos en la «noche del 30 al 31 de julio» ${ }^{48}$, sin aproximaciones horarias concretas; finalmente, aquellos que coinciden con el sumario militar analizado: en la madrugada del 31 de julio ${ }^{49}$. Esta datación ulterior es la que consideramos más acertada, tanto por la precisión habitual derivada de la minuciosidad militar como por constituir la más abundante en las obras consultadas; dos de éstas son, además, las de más reciente publicación y consecuentemente las de registros presumiblemente más actualizados.

46 Raimundo CASTRO, Los imprescindibles..., p. 442

47 Secundino SERRANO, Maquis..., p. 177: «... había encontrado la muerte el 30 de julio de 1946».

48 Ángel PRIETO, Guerrilleros de la libertad..., p. 136. Francisco MORENO, La resistencia armada..., p. 395.

49 Según el sumario militar el encuentro tuvo lugar a las dos horas y treinta minutos del día 31 de julio de 1946: AGHD, sumario n. ${ }^{\circ}$ 137.443, - certificación del capitán instructor, folio $2 ;$ - certificación literal del acta de defunción, folio $6 ;-$ declaración del cabo primero Comandante del Puesto de Serradilla, folio 6 vuelto; escrito del capitán instructor dirigido al Juez Eymar, folio 10; - escrito del coronel Eymar, Juez Especial de los Delitos de Espionaje y Comunismo de la $1 .{ }^{\text {a }}$ Región Militar, dirigido al Consejo de Guerra, folio 20. Julián CHAVES, Huidos y Maquis..., p. 146. Julián CHAVES, Guerrilla y Franquismo..., p. 154. Benito DÍAZ, Huidos y guerrilleros..., p. 427. Justo VILA, La guerrilla antifranquista..., p. 153. 


\section{Conclusiones}

Como conclusión podemos apuntar en primer lugar que la localización de la causa militar resulta de notable importancia. Como quiera que no esté presente en ninguna de las obras sobre el movimiento guerrillero, desde mi punto de vista, supone un aporte interesante para el estudio de la resistencia armada contra el Dictador. Obviamente, como cualquier otra documentación proveniente de la órbita franquista, ha de estudiarse teniendo en cuenta esa perspectiva, es decir, analizar el sumario conscientes de la verticalidad monolítica característica del Régimen. Porque no hay duda que todos los estamentos del franquismo, cuando se trataba de combatir al «bandolerismo», se alineaban sin fisuras para lograr su erradicación.

En el plano judicial se promulgaron una serie de normas que pretendían dar visos de legalidad a una situación a todas luces dictatorial. Se trataba de un Estado personalista encarnado en la figura del todopoderoso Caudillo y sujeto a una legislación derivada del espíritu y las directrices del Alzamiento Nacional. Así, la Justicia se fundamentaba en los procesos sumarísimos de los Consejos de Guerra, por tanto, la Autoridad Militar también lo era Judicial. Soportada por esta vorágine reglamentaria, la Justicia Militar se empleo a fondo para hacer cumplir la legalidad emanada del Estado franquista, tendente sobre todo a erradicar el mal «rojo» a base de una represión atroz.

Dentro de estas leyes, me atrevo a destacar las relacionadas a continuación. La Ley de Responsabilidades Políticas se publicó en los meses finales de la Guerra Civil, pero se hizo pensando en la etapa posterior cuando, una vez lograda la victoria de los sublevados, la represión contra el vencido se llevó a cabo a lo largo y ancho de la geografía española. A continuación, se dictó la Ley contra la Masonería y el Comunismo para acabar con tan «perniciosas» organizaciones y erradicar los males causados por ellas. Por último, dentro de la importancia para el asunto que nos concierne, la Ley de Seguridad del Estado, el Código Penal y el de Justicia Militar y, sobre todo, la Ley de Represión del Bandidaje y Terrorismo de 1947, se pueden catalogar como herramientas primordiales para destruir a la resistencia, principalmente la llevada a cabo por el movimiento guerrillero antifranquista. Qué para conseguir tal objetivo habrían de utilizarse métodos tan expeditivos como el uso de la tortura, poco importaban si con ello se conseguía aniquilar a un movimiento armado que se atrevía a desafiar al todopoderoso Caudillo. Por consiguiente, ha de tenerse en cuenta esta singularidad a la hora de estudiar el expediente expuesto. 
En segundo lugar, el análisis del sumario elaborado por la muerte del jefe guerrillero nos aporta un desarrollo secuencial y detallado de los hechos. La preparación del operativo para su captura en un sitio concreto, con la disposición de la fuerza policial en tres grupos perfectamente parapetados para conseguir su objetivo, nos abocan a la siguiente convicción: la Guardia Civil tenía una información precisa para actuar de tal forma. Si bien parece probable que esos datos tan sensibles provinieran del entorno guerrillero, no es posible establecer con seguridad su origen concreto. La actuación de la fuerza policial, fueran ciertos o no los avisos dados por el cabo primero jefe de los emboscados, deja poco margen para la duda: advertida la presencia del guerrillero se llevó a cabo una descarga cerrada que acabaron con su vida de forma instantánea.

Ciertamente, en la zona centro del país, y muy especialmente en el septentrión cacereño, durante el año 1946 proliferaron de manera asombrosa las traiciones de guerrilleros y colaboradores que debilitaron sobremanera al movimiento maquis. Las fuerzas represoras del franquismo, con la Guardia Civil a la cabeza, supieron aprovechar esa coyuntura por ellos mismos propiciada para asestar un duro golpe al fenómeno que nos atañe.

Así, tras la caída el 31 de julio de 1946 de «El Francés», se produjeron una serie de hechos que causaron un gran revés a la resistencia. A primeros de agosto de ese mismo año, se detiene al guerrillero Amancio Nieto Calero «El Abuelo» debido a las declaraciones realizadas a la Guardia Civil de Ciudad Real por el ex guerrillero «Viruta», el cual se encontraba colaborando activamente con las fuerzas represivas. El día 6 del mismo mes, tiene lugar el asalto al campamento que la partida de «El Compadre» tenía en el lugar denominado Canchales del Ramo, del término municipal de Pozuelo de Zarzón (Cáceres). Como consecuencia del ataque realizado por la Guardia Civil al citado campamento, murieron los cinco guerrilleros componentes de la partida y el enlace que la misma tenía en la población. En este mismo mes, y a causa de la documentación encontrada en el campamento atacado, se llevó a cabo la detención de numerosos enlaces que prestaban sus servicios por los pueblos de la comarca. Pocos días después, el 12 de agosto, se desbarata otra red de enlaces que los guerrilleros tenían en la finca Torre de Paniagua perteneciente al término municipal de Gargüera, también en la provincia cacereña. El atestado instruido por el capitán Carrasco, jefe de la primera compañía con sede en Plasencia, señala el chiva- 
tazo como inicio de las pesquisas. Finalmente, el 21 del mismo mes, se vuelve a detener a dos colaboradores de Plasencia y Cabezabellosa, desactivando un posible atentado contra el mencionado capitán. Como vemos, toda una batería de detenciones y desarticulaciones de bases que tuvieron un efecto demoledor para la guerrilla. Los miembros de la Benemérita hostigaron de tal manera a los colaboradores y enlaces que el movimiento armado antifranquista quedó amputado de los puntos de apoyo tan necesarios como imprescindibles para llevar a cabo tan ingente tarea.

Por último, las discrepancias encontradas entre las obras analizadas y la causa jurídico militar y hasta las existentes entre los propios autores, lejos debilitar el análisis, lo fortalecen sobremanera. Ya que las versiones variadas aumentan los elementos de juicio y mejoran las conclusiones extraídas de un estudio riguroso de las mismas. En algunos casos, como el de la muerte instantánea de «El Francés», el modus operandi y el número de componentes de de la fuerza pública, parece haber quedado plenamente clarificadas. Pero en otros, como el de los guerrilleros acompañantes y su posible huida precipitada abandonando algunas armas, no han podido delimitarse con nitidez. Cuestiones estas últimas en cualquier caso de menor importancia para la investigación. En lo que sí están de acuerdo todas las fuentes es que la muerte del Jefe de la 12. ${ }^{a}$ División del Ejército Guerrilleros de Extremadura-Centro supuso un gran mazazo para la resistencia armada contra el régimen franquista.

No obstante, con la venida del último jefe de la Agrupación extremeña «Fabián» (en septiembre de 1946), pareció haber llegado cierto resurgimiento, pero pronto se comprobó que no era más que un espejismo. Tras algunos éxitos iniciales, entre los que cabe destacar la toma del pueblo de Jarilla (6 de noviembre de 1946), a mediados de 1947 fue detenido y el 21 de noviembre de 1947 ejecutado en Madrid mediante garrote vil. La lucha armada antifranquista en la región, sobre todo en la provincia de Cáceres, llegó a su fin. Aunque durante algún tiempo persistieron algunas partidas aisladas, su único objetivo era sobrevivir en un mundo hostil, sin aliados y acosados por unas fuerzas represoras exultantes por los éxitos conseguidos y sedientas de asestar el último golpe a un movimiento con un desenlace fatídico. Así, a mediados de 1947 se puede dar por concluido todo signo organizado de resistencia armada contra el régimen de Franco en esta provincia. 


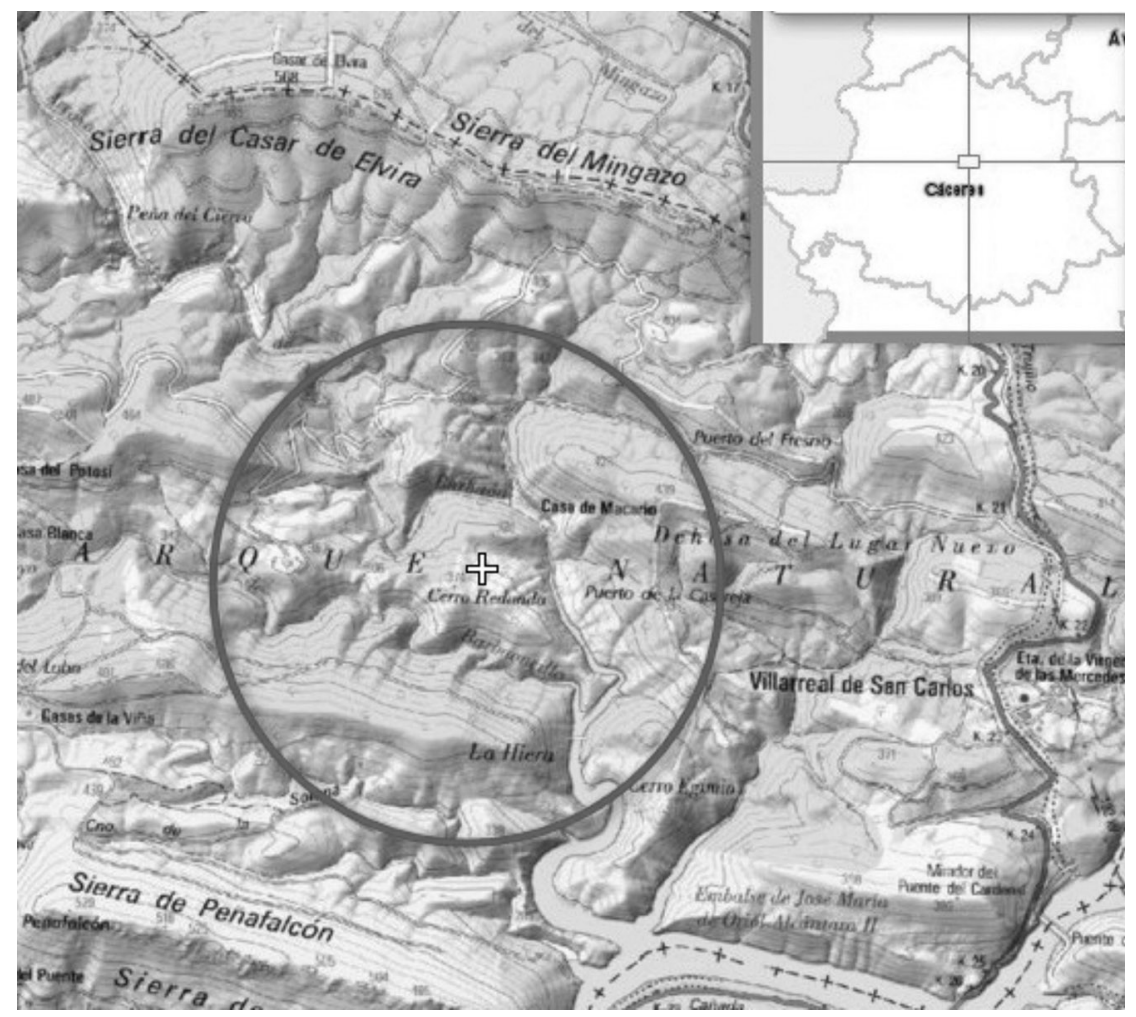

\section{Mapa 2}

Área donde tuvo lugar el enfrentamiento entre la Guardia Civil y el guerrillero que resultó muerto.

Fuente: Elaboración propia sobre un mapa del Instituto Geográfico Nacional.

\section{Fuentes}

Archivo General e Histórico de Defensa (AGHD).

Archivo Histórico del Partido Comunista de España (AHPCE).

Servicio de Estudios Históricos de la Dirección General de la Guardia Civil (SEHGC). 


\section{Bibliografía consultada}

CASTRO RAIMUNDO, Los imprescindibles: la novela de los últimos maquis, Madrid, La Esfera de los Libros, 2016.

CHAVES Julián, Guerrilla y Franquismo. Memoria viva del maquis Gerardo Antón (Pinto), Badajoz, Editora Regional de Extremadura, 2005

CHAVES Julián, Huidos y Maquis. La actividad Guerrillera en la Provincia de Cáceres, 1936-1950, Cáceres, Institución Cultural «El Brocense», 1994

DÍAZ BENITO, Huidos y guerrilleros antifranquistas en el centro de España, 1939-1955, Toledo, Editorial Tilia, 2011.

DÍAZ BENITO, «Los huidos en .la provincia de Cáceres (1940-1944)», GONZÁLEZ, J.R., y AGUADO, R., -Coordinadores - , Extremadura durante el primer franquismo (1939-1959,) Badajoz, Diputación de Badajoz, 2010.

MORENO FRANCISCO, La resistencia armada contra Franco. Tragedia del maquis y la guerrilla. El Centro-Sur de España. De Madrid al Guadalquivir, Barcelona, Crítica, 2001.

MORENO FRANCISCO, «Lagunas en la memoria y en la historia del maquis», HISPANIA NOVA Revista de Historia Contemporánea, número 6, 2006.

PRIETO ÁNGEL, Guerrilleros de la libertad, Madrid, Oberón Grupo Anaya S.A., 2004.

SERRANO SECUNDINO, Maquis, Historia de la Guerrilla Antifranquista, Madrid, Ediciones Temas de Hoy, 2001.

VILA Justo, La guerrilla antifranquista en Extremadura, Badajoz, Universitas Editorial, 1986.

\section{Recursos electrónicos}

lusipedia.blogspot.com /2009/01/el-frances.htm [23/01/2017].

ORTIZ MATEOS, A. http://lahistoriaenlamemoria.blogspot.com [23/01/2017]. 


\section{Datos del autor}

José Mariano Agudelo Blanco (agudelo@ono.com) es licenciado en Historia y diplomado de Estudios Avanzados (DEA) en Historia Contemporánea por la UNED. Actualmente doctorando por la Universidad de Extremadura (UEX). Su línea de investigación se centra en la resistencia armada antifranquista en Extremadura y Castilla y León. Recientemente ha participado en el Seminario Internacional: Mecanismo de Control Social y Político en el Primer Franquismo de la UEX, con la presentación de la comunicación: Las causas militares en la represión del maquis extremeño.

Últimas publicaciones: "¡Garrote vil! Para el último jefe de la guerrilla extremeña» y "El guerrillero apodado "Lobo": ¿infiltrado, confidente o delator?» de la Revista de Estudios Extremeños. Colaboraciones en medios de prensa como El Adelantado de Segovia y Extremadura Progresista. 